\title{
EVALUATING THE ADVANCED LIFE DEFERRED ANNUITY - AN ANNUITY PEOPLE MIGHT ACTUALLY BUY
}

\author{
Guan Gong and Anthony Webb \\ CRR WP 2007-15 \\ Released: September 2007 \\ Draft Submitted: September 2007 \\ Center for Retirement Research at Boston College \\ Hovey House \\ 140 Commonwealth Avenue \\ Chestnut Hill, MA 02467 \\ Tel: 617-552-1762 Fax: 617-552-0191 \\ http://www.bc.edu/crr
}

* Guan Gong is an Associate Professor at the Shanghai University of Finance and Economics. Anthony Webb is a research economist at the Center for Retirement Research at Boston College. The research reported herein was performed pursuant to a grant from the U.S. Social Security Administration (SSA) funded as part of the Retirement Research Consortium. The opinions and conclusions expressed are solely those of the authors and should not be construed as representing the opinions or policy of SSA, any agency of the Federal Government, or Boston College. The authors would like to thank Alicia Munnell for her very helpful comments and Wei Sun for research assistance.

(C) 2007, by Guan Gong and Anthony Webb. All rights reserved. Short sections of text, not to exceed two paragraphs, may be quoted without explicit permission provided that full credit, including $(\odot$ notice, is given to the source. 


\title{
About the Center for Retirement Research
}

The Center for Retirement Research at Boston College, part of a consortium that includes parallel centers at the University of Michigan and the National Bureau of Economic Research, was established in 1998 through a grant from the Social Security Administration. The Center's mission is to produce first-class research and forge a strong link between the academic community and decision makers in the public and private sectors around an issue of critical importance to the nation's future. To achieve this mission, the Center sponsors a wide variety of research projects, transmits new findings to a broad audience, trains new scholars, and broadens access to valuable data sources.

\author{
Center for Retirement Research at Boston College \\ Hovey House \\ 140 Commonwealth Avenue \\ Chestnut Hill, MA 02467 \\ phone: 617-552-1762 fax: 617-552-0191 \\ e-mail: crr@bc.edu \\ www.bc.edu/crr
}

\author{
Affiliated Institutions: \\ American Enterprise Institute \\ The Brookings Institution \\ Center for Strategic and International Studies \\ Massachusetts Institute of Technology \\ Syracuse University \\ Urban Institute
}




\begin{abstract}
Although annuities provide longevity insurance that should, in theory, be attractive to risk-averse households facing an uncertain lifespan, rates of voluntary annuitization remain extremely low. We evaluate a proposed annuity product, the Advanced Life Deferred Annuity, an annuity purchased at retirement, providing an income commencing in advanced old age. Using numerical optimization techniques, we show that this product would provide a substantial proportion of the longevity insurance provided by an immediate annuity, at a small fraction of the cost. At plausible levels of actuarial unfairness, households should prefer it to both immediate and postponed annuitization, and an optimal decumulation of unannuitized wealth. We show that few households would suffer significant losses were it used as a 401(k) plan default.
\end{abstract}




\section{Introduction}

Immediate annuities provide insurance against outliving one's wealth. Previous research has shown that this insurance ought to be valuable to risk-averse households facing an uncertain lifespan. But rates of voluntary annuitization remain extremely low.

Many explanations have been offered for retired households' reluctance to annuitize. ${ }^{1}$ Prominent is that annuities suffer from a considerable degree of actuarial unfairness. That is, for the average household, the expected value of the income, discounted by a rate of interest and annual survival probabilities, is considerably less than the premium paid. But it seems likely that households are also influenced by a possibly not wholly rational reluctance to give up access to their life savings.

In the past, low rates of voluntary annuitization were not a matter of great policy concern because most households held substantial proportions of their wealth in preannuitized form through Social Security and defined benefit pensions. However, the displacement of defined benefit plans by $401(\mathrm{k}) \mathrm{s}$ and projected reductions in Social Security replacement rates will increase the importance of a well-functioning and attractive annuity market.

This paper evaluates a proposal, first brought to the attention of the academic community by Milevsky (2005), for an innovative annuity product - the Advanced Life Deferred Annuity (ALDA). The ALDA is an inflation protected annuity that would be purchased at retirement or even earlier. But in contrast to a traditional annuity, income payments would only start at some advanced age, (say) 75, 80, or 90 .

We compare this product with the alternatives of immediate annuitization on retirement, postponing the purchase of an annuity until some advanced age, and undertaking an optimal decumulation of unannuitized wealth. We show it has three important advantages. First, it enables households to preserve liquidity at least until the ALDA payments commence, thus overcoming a potentially important psychological barrier to annuitization. We calculate that a household planning to smooth consumption through its retirement would need to allocate only 15 percent of its age 60 wealth to an ALDA with payments commencing at age 85, holding the remainder of its wealth in unannuitized form to finance consumption from age 60 to 85 . Second, although a risk-

\footnotetext{
${ }^{1}$ For a survey of possible explanations, see Brown and Warshawsky (2001).
} 
averse household facing an uncertain lifespan would prefer the full longevity insurance provided by an actuarially fair annuity to the partial longevity insurance provided by an actuarially fair ALDA, at prevailing annuity and projected ALDA levels of actuarial unfairness, the household would prefer the ALDA to both full annuitization and an optimal decumulation of unannuitized wealth. Third, the above comparisons assume that households undertake an optimal decumulation of unannuitized wealth carefully trading off the risk of outliving its wealth against the cost, in terms of foregone consumption, of decumulating its wealth too conservatively. In practice, they probably use rules of thumb to the extent that they plan at all. We show that simple rules of thumb that perform almost as well as the optimal can be applied to the management of wealth decumulation over a period ending on the date that the ALDA income commences. In contrast, widely advocated rules for managing the decumulation of unannuitized wealth over an entire lifetime are highly suboptimal. ALDAs therefore have the potential to improve and simplify the process of retirement wealth decumulation.

Finally, we consider the extent to which government and employers should encourage the take-up of ALDAs by, for example, making them a default option in 401(k) plans. A potential concern is that defaulting retirees into an ALDA might harm those who would rationally choose not to purchase. In Gong and Webb (2006), we calculated subjective mortality tables for each individual in the Health and Retirement Study (HRS) based on their self-reported survival probabilities. ${ }^{2}$ Using this data, we show that in expected utility terms almost all HRS households would be better off purchasing an ALDA than undertaking an optimal decumulation of unannuitized wealth.

The remainder of the paper is organized as follows. Section Two explains how the ALDA would work and what it would cost. Section Three calculates how much longevity insurance an ALDA would provide. Section four compares ALDAs, annuities, and optimal decumulations of unannuitized wealth in practice. Section Five considers whether ALDAs can safely be used as a default in 401(k) plans, and Section Six concludes.

\footnotetext{
${ }^{2}$ The HRS is a panel of over 7,000 individuals born between 1931 and 1941, and their spouses of any age.
} 


\section{How Would an ALDA Work and What Would It Cost?}

The concept was brought to our attention by Milevsky (2005) who envisaged an inflation protected deferred annuity that would be purchased by installments over an individual's working life, but which would only come into payment at an advanced age, (say) 75 or older. He reports that although several insurance companies have either already launched or are about to launch variants of the ALDA, their design features increase their cost and "detract from the ultimate objective, which is to encourage annuitization at the lowest possible cost," (Milevsky, page 118).

One possible drawback to this idea is the likely reluctance of individuals to contribute during their working lives towards the cost of a product that would only provide benefits in advanced old age. Instead, such a product might be more attractive if purchased at or near retirement. ${ }^{3}$ We therefore estimate the cost of an inflation-protected joint life and two thirds survivor ALDA purchased with a lump sum at either age 60 or 65.

ALDA prices in the voluntary market will depend on the insurance company's expenses and assumptions regarding mortality rates and investment returns. We assume that they will calculate mortality rates using the Annuity 2000 basic life table, projected using Projection Scale AA, and investment returns using the current yield on long dates TIPS. ${ }^{4}$ We recover expense rates by calculating the money's worth of currently available inflation protected annuities, the expected present value of the payments discounted by an interest rate and annual survival probabilities, using the same assumed mortality and interest rates. ${ }^{5}$ To illustrate the possible distributional consequences of mandatory purchase of ALDAs using, for example, part of the balances accumulated in Social Security individual accounts, we also calculate actuarially fair ALDA prices assuming

\footnotetext{
${ }^{3}$ Annuities are able to offer a higher return than similar unannuitized investments because their return is boosted by "mortality credits," the re-allocation of money in the annuity pool from those who die to those who survive. Mortality rates, and therefore mortality credits, are relatively low at younger ages, and as a result, the additional benefit from purchasing an ALDA before retirement is correspondingly small. ${ }^{4}$ These and other life tables can be downloaded from the Society of Actuaries website www.soa.org and analyzed using the SOA's Table Manager software. A basic life table shows current period mortality rates without any conservative margin. Published life tables are period tables - they show mortality rates of people of various ages alive in a particular reference year. Projection scales are used to forecast mortality rates in future years and thereby construct cohort tables forecasting mortality rates of people born in a particular reference year.

5 The choice of mortality table, and in particular, whether it has a conservative margin, has little effect on our results because the same table is used to both recover the expense load and calculate ALDA prices.
} 
population mortality as forecast by the Social Security Administration for the relevant birth cohorts (1947 for 60 year olds and 1942 for 65 year olds) and zero expenses. ${ }^{6}$

It is possible that an insurance company might experience a greater or lesser degree of adverse selection on ALDAs than on conventional annuities, rendering inappropriate the use of annuitant life tables. We note that Finkelstein and Poterba (2004) find evidence of selection between annuity products in the United Kingdom annuity market, with greater selection in increasing and inflation linked annuities, where the payments are back-loaded and therefore disproportionately valuable to low mortality types. ALDAs which also have back-loaded payments may likewise suffer from greater than average levels of adverse selection. But if ALDAs were attractive to high mortality types who currently shun the annuity market, the level of adverse selection on ALDAs might be lower than on regular annuities.

A complication arises in that an insurance company's ALDA obligations would extend beyond the maturity date of the longest maturity TIPS, so that it would be exposed to reinvestment risk. Although the U.S. Treasury has recommenced issuing non inflation-indexed thirty year bonds, thirty year TIPS are no longer available, and the longest dated TIPS matures in 2032. Reinvestment risk is a more serious problem for ALDAs than for regular annuities because ALDA payments are concentrated at advanced ages. We assume that the insurance company is able to reinvest its assets at a real rate of return equal to that currently observed at the long portion of the yield curve.

Alternatively, ALDA purchasers could be required to participate in investment risk.

We do not consider aggregate mortality risk. Friedberg and Webb (2007) use the Lee-Carter (1992) model to evaluate the aggregate mortality risk faced by annuity providers. They show that aggregate mortality risk is essentially uncorrelated with the returns on the "market portfolio" as measured by the S\&P500. Applying the capital asset pricing model, they argue that it should be possible, at least in theory, to transfer aggregate mortality risk to the financial markets at very low cost. Alternatively, ALDA purchasers could be required to participate in this risk.

\footnotetext{
${ }^{6}$ The level of actuarial unfairness would depend on the precise design of the program. Conditioning on gender, there is a positive correlation between longevity and lifetime income, and therefore annuitizable account balance, but women, who on average have lower lifetime incomes than men, also have lower mortality.
} 
As of 22 February 2007, the yield on a Vanguard joint life and two thirds survivor annuity inflation protected annuity, with payments made annually advance, commencing at age 65 , was 4.87 percent. $^{7}$ The average yield on long dated TIPS at that time was 2.35 percent. Using the Annuity 2000 mortality table and Projection Scale AA, we calculate that the money's worth of the Vanguard annuity to a household with annuitant mortality was 88.8 percent at both age 60 and 65 . At ages 70, 75, 80, 85 and 90 it was 89.3, 88.5, 83.9, 80.4 and 79.1 percent respectively.

Vanguard appears to offer a lower money's worth for annuities commencing at older ages. One possible explanation is that AIG, their insurers, believe they will experience a greater degree of adverse selection on such annuities than indicated by life tables. Alternatively, they might believe that Projection Scale AA overstates the likely rate of mortality improvements at older ages. But Projection Scale AA forecasts a decreasing rate of mortality declines at the oldest ages, contrary to the forecasts of the Social Security Administration and those obtained using the Lee-Carter model (Lee and Carter 1992). Yet another possible explanation is AIG is assuming a higher return than the TIPS yield. At a real interest rate of four percent, the money's worth would be about 75 percent regardless of commencement age. Vanguard might even believe that it had more pricing power at older ages.

These competing explanations have different implications for the likely money's worth of ALDAs. In the absence of strong evidence supporting any particular explanation, we prefer not to place undue weight on the increase in actuarial unfairness at older ages. We therefore assume that insurance companies will price ALDAs in accordance with projected annuitant life tables, using TIPS interest rates, and at a money's worth of 85 percent to households with annuitant mortality. This results in ALDAs commencing at ages 70, 75, 80, 85, and 90 costing \$14.01, \$9.87, \$6.42, \$3.70, and $\$ 1.76$ per dollar of income, if purchased at age 60 , and $\$ 15.91, \$ 11.17, \$ 7.24, \$ 4.14$, and $\$ 1.95$ at age 65. Assuming an age related pattern of actuarial unfairness, ALDAs would be slightly cheaper at younger ages and slightly more expensive at older ages. But

\footnotetext{
${ }^{7}$ Vanguard is the only insurer currently offering inflation protected immediate annuities. The product appears to be somewhat less actuarially fair than nominal annuities, consistent with the findings of Finkelstein and Poterba (2004). TIAA-CREF offer a variable immediate annuity with the return linked to that on TIPS, but this does not provide complete inflation protection because the return also depends on movements in interest rates.
} 
the magnitude of the change would not be sufficient to affect our ordering of asset decumulation strategies. By comparison, actuarially fair ALDAs commencing at ages 70, $75,80,85$, and 90 would cost $\$ 9.88, \$ 6.60, \$ 3.99, \$ 2.08$, and $\$ 0.86$ per dollar of income if purchased at age 60 , and $\$ 11.48, \$ 7.58, \$ 4.55, \$ 2.34$, and $\$ 0.95$ at age 65 .

\section{How Much Longevity Insurance Would an ALDA Provide?}

The literature - for example Mitchell, Poterba, Warshawsky, and Brown (1999), Brown and Poterba (2000), and Dushi and Webb (2004) uses numerical optimization techniques to calculate "annuity equivalent wealth" (AEW), a measure the value of the longevity insurance provided by annuities. AEW equals the factor by which unannuitized wealth must be multiplied so that the household can enjoy the same expected utility through an optimal decumulation of its unannuitized wealth as it would enjoy were it to purchase an actuarially fair annuity with that wealth.

We follow this literature by calculating both annuity and ALDA equivalent wealth. We define ALDA equivalent wealth as equaling the factor by which unannuitized wealth must be multiplied so that the household can enjoy the same expected utility through an optimal decumulation of its unannuitized wealth as it would enjoy were it to purchase an actuarially fair ALDA commencing at a specified age with part of that wealth. The calculation is more complex than that of AEW because we must jointly determine the optimal proportion of initial wealth to spend on the ALDA and the optimal decumulation of the household's remaining wealth from retirement until the age the ALDA payments commence.

We follow the literature by assuming a constant relative risk aversion utility function of the following form:

$$
U_{m}\left(C_{t}^{m}, C_{t}^{f}\right)=\frac{\left(C_{t}^{m}+\lambda C_{t}^{f}\right)^{1-\gamma}}{1-\gamma}, U_{f}\left(C_{t}^{f}, C_{t}^{m}\right)=\frac{\left(C_{t}^{f}+\lambda C_{t}^{m}\right)^{1-\gamma}}{1-\gamma}
$$

where $\lambda$ measures the jointness of consumption, $C_{t}^{m}, C_{t}^{f}$ denote the consumption of the husband and wife at time $t$, and $\gamma$ is the coefficient of risk aversion. When $\lambda$ equals one, all consumption is joint. When $\lambda$ equals zero, none of the household's consumption is joint. The household's expected utility equals each period's utility, multiplied by survival probabilities and discounted by a rate of time preference that equals the interest 
rate. For simplicity and to facilitate comparison with previous research, we ignore preannuitized wealth, or alternatively assume that pre-annuitized wealth is used to finance basic consumption that does not contribute to the household's utility.

To calculate AEW, we proceed as follows. We first calculate the household's expected utility if it buys an actuarially fair annuity at retirement. We then close the annuity market. We use numerical optimization techniques to calculate an optimal decumulation of the household's wealth and the expected utility of that decumulation plan. We then calculate the amount by which the household's wealth must be increased so that its expected utility equals that obtainable when it annuitizes. This increased amount is divided by the household's original wealth to obtain the household's annuity equivalent wealth. We assume that the household and the insurance company are both able to invest in a single risk-free asset yielding 2.35 percent, the average yield on long dated TIPS in February 2007, and that this also equals the household's rate of time preference.

The calculation of ALDA equivalent wealth is analogous. For ALDAs that commence payment at ages $70,75,80,85$, and 90 , we determine the optimal proportion of initial wealth to spend on the ALDA, and the optimal decumulation strategy over the period ending on the date that the ALDA income commences. ${ }^{8}$ We then close the ALDA market and calculate the amount by which the household's wealth must be increased so that its expected utility equals that obtainable when it purchases an ALDA.

In practice, households that choose not to annuitize don't calculate decumulation strategies using numerical optimization techniques. Little is known about how households make asset decumulation decisions in retirement, but it seems plausible that households use rules of thumb, to the extent that they plan at all. ${ }^{9}$ Some of these are likely to be highly sub-optimal. For example, some retirement planning tools suggest that households should accumulate sufficient wealth by retirement to finance consumption over their life expectancy. Such a strategy offers a 50 percent chance of

\footnotetext{
${ }^{8}$ A particular issue is whether we should impose the constraint that the household consumes all of its unannuitized wealth by the time the ALDA payments commence. It can sometimes be optimal not to do so - for example, if a member of the household dies shortly before that date. We think it is unreasonable to expect a household to solve a decumulation problem of such complexity, and assume that all wealth is consumed by that time.

${ }^{9}$ DeNardi, French, and Jones (2006) emphasize the importance of the health and longevity risk and the impact of social insurance.
} 
destitution in old age. It is sometimes asserted that annual consumption in retirement should be no more than four percent of initial wealth, because at that withdrawal rate, households have only a small chance of outliving their wealth. In the absence of a bequest motive, this strategy is clearly sub-optimal because the household can obtain a higher income with zero probability of outliving its wealth by buying an inflation protected annuity.

One advantage of the ALDA over a decumulation of unannuitized wealth is that it transforms the complex task of decumulating one's wealth over an uncertain lifespan into the much simpler task of decumulating over a fixed period ending on the date that the ALDA payments commence. In calculations discussed later, we show that a household does very nearly as well consuming an equal amount each period prior to the date the ALDA commences as it would do if it attempted to consume the optimal amount each period, taking account of the annual survival probabilities of each spouse. Of course, the household that attempts an optimal decumulation can end up a great deal worse off if it gets its calculations wrong.

The first line of each of the two panels of Table One shows our calculations of annuity equivalent wealth at ages 60 and 65, assuming coefficients of risk aversion of two to five. At age 60, annuity equivalent wealth varies from 1.216 at a coefficient of risk aversion of two, to 1.291 at a coefficient of five. ${ }^{10}$ Annuity equivalent wealth is higher at older commencement ages reflecting lower life expectancy - an infinitely lived household would consume only the interest on its investment, would place no value on longevity insurance, and would have an AEW of one, regardless of coefficient of risk aversion.

The following lines of each of the two panels show ALDA equivalent wealth for ALDAs with payments commencing at ages 70 to 90, assuming that the household follows an optimal decumulation strategy prior to the ALDA income commencing. Immediately below the results for each commencement age, we show the percentage of the value of the full longevity insurance provided by the annuity that is provided by the

\footnotetext{
${ }^{10}$ Our results differ slightly from those of Brown and Poterba (2000). We obtain almost identical results when we calculate AEW for their somewhat earlier birth cohort, using their assumed values for $\lambda$ and the rate of time preference and attribute the residual to differences in assumptions regarding the timing of consumption.
} 
ALDA. Below the results and percentages, we show the proportions of initial wealth that the household should optimally allocate to the purchase of the ALDA.

ALDA equivalent wealth is, of course, less than annuity equivalent wealth, and is lower at older commencement ages. But even at age 85, the ALDA provides more than half the longevity insurance provided by the annuity, at a fraction of the cost in terms of foregone liquidity. ${ }^{11}$ Even at a commencement age of 90, an ALDA purchased at age 60 yields ALDA equivalent wealth equals 1.138 , or 47.5 percent of annuity equivalent wealth, assuming a coefficient of risk aversion of five. But the household will optimally spend only 4.3 percent of its initial wealth on purchasing the ALDA.

Corresponding results for the naive strategy are reported in Table Two.

Following the naïve strategy reduces ALDA equivalent wealth. The under-performance increases with commencement age, but is quite modest even at a commencement age of 90. At a coefficient of risk aversion of five, a purchase age of 60 , and a commencement age of 90, ALDA equivalent wealth under the naive strategy equals 1.119 , or 40.9 percent of annuity equivalent wealth, compared with 1.135 or 47.5 percent under the naïve strategy. At a commencement age of 80, the corresponding figures are 1.227, 78.2 percent, 1.234, and 80.6 percent. We conclude that the substantial costs in calculating and following the sophisticated strategy would not be justified by the modest additional benefits.

\section{ALDAs and Annuities in Practice}

In practice, annuities are actuarially unfair, reflecting both adverse selection and expense loads. ${ }^{12}$ In this section, we recalculate annuity and ALDA equivalent wealth for each of the strategies described in the previous section, taking account of actual and projected levels of actuarial unfairness.

\footnotetext{
${ }^{11}$ The additional liquidity provided by the ALDA is largely illusory. The household only enjoys additional liquidity until it has exhausted its financial wealth and it is at advanced ages when medical costs are both large and uncertain that liquidity will have the greatest value.

${ }^{12}$ Adverse selection refers to the impact of prices in insurance markets of higher than average rates of purchase by high risk (in the context of annuities, low mortality) households whose risk cannot be costeffectively identified by the insurer. Adverse selection may occur not only as a result of purchasers having private information about their risk type, but also when the probability of purchase is affected by unobserved characteristics that are correlated with risk.
} 
Mitchell, Poterba, Warshawsky, and Brown (1999) calculated that in 1995 the money's worth of a traditional level immediate annuity was only about 75 or 85 cents on the dollar to a household with population average mortality, depending on whether the corporate or Treasury bond interest rate is used. In Section Three, we reported annuity equivalent wealth values of between 1.216 and 1.291 at age 60 , depending on the coefficient of risk aversion. Multiply these values by 0.75 to 0.85 , and it is easy to see that full annuitization on retirement is going to be of marginal value to the average household.

ALDAs are likely to be even more actuarially unfair that traditional annuities to the average household. ALDAs only start to pay benefits at advanced ages, and people who purchase ALDAs likely have a much higher than average probability of surviving to such ages.

But actuarial unfairness is a poor indication of the relative attractiveness of ALDAs. As shown earlier, households will spend only a small proportion of their wealth on an ALDA, so the cost of actuarial unfairness may be quite small in dollar terms.

Table Three shows the equivalent wealth of various strategies relative to a base case of undertaking an optimal decumulation of unannuitized wealth, taking account of actuarial unfairness. Strategies with higher equivalent wealth are preferred, and those with values of greater than one are preferred to the base case. The table reports results for coefficients of risk aversion of two, three, four, and five, retirement ages of 60, and 65, and assumes no pre-annuitized wealth and are for households with population mortality for the 1947 and 1942 birth cohorts, respectively.

We assume age 22 February 2007 prices for immediate annuities purchased at ages 60 and 65 and the ALDA prices reported in section Two. To ensure comparability with ALDAs, we further assume that households that defer annuitization eventually face annuity prices that have the same 85 percent money's worth used to calculate ALDA prices. But as discussed in Section Two, annuities purchased at older ages currently have somewhat lower money's worths. An alternative assumption might be that both ALDA and annuity money's worths decline at older ages. In results that are not reported, we found that the ranking of the alternative strategies was unchanged under reasonable alternative assumptions. Substantial changes in the prices of ALDAs with payments 
commencing at advanced ages have relatively little effect on the optimal strategy because the dollar amount spent on the ALDA is relatively small regardless.

To continue, the first row of Table Three reports the value of full annuitization immediately on retirement. As anticipated, this is of marginal benefit to the household. At an assumed retirement age of 60 , the household is 3.3 percent worse off (1.00 minus 0.967) at a coefficient of risk aversion of two, and 2.6 percent better off at a coefficient of risk aversion of five.

An alternative to full annuitization at retirement is to undertake an optimal partial decumulation of unannuitized wealth, and then purchase an annuity at some older age. Dushi and Webb (2004) calculated that at prevailing levels of actuarial unfairness, it was optimal for married couples with population mortality and no pre-annuitized wealth to delay annuitization until age 74 at a coefficient of risk aversion of two, and 83 at a coefficient of risk aversion of five. ${ }^{13}$ Until those ages, the mortality credits were insufficient to offset the expense load.

The second row of the table reports results for annuitization at the optimal age. Consistent with Dushi and Webb (2004), the household is, regardless of coefficient of risk aversion, better off postponing annuitization than either annuitizing immediately on retirement or undertaking an optimal decumulation of unannuitized wealth.

Rows three to seven show results when the household purchases an ALDA at ages $70,75,80,85$, and 90 . We assume that the household allocates the optimal proportion of its wealth to the ALDA, and consumes the optimal amount every period from retirement until the age the ALDA income commences. With one exception (a commencement age of 70 and a coefficient of risk aversion of two), the household invariably prefers an ALDA to an optimal decumulation of unannuitized wealth, sometimes by a substantial amount. More risk-averse households place a higher value on ALDAs, and the optimal commencement age is around 85, regardless of the household's degree of risk-aversion or age of purchase. A household that purchases an ALDA at 60 with payments commencing at 85 is 5.9 percent better off than one undertaking an optimal decumulation, assuming a coefficient of risk aversion of two, and 10.3 percent better off at a coefficient

\footnotetext{
${ }^{13}$ In practice, a household pursuing this strategy runs the risk that annuity rates may decline as a result of adverse movements in interest rates and mortality assumptions.
} 
of five. Regardless of coefficient of risk aversion, a household that purchases an ALDA with payments commencing at the optimal age is better off than a household that delays annuitization, reflecting the fact that an ALDA earns mortality credits from retirement, whereas a household that delays annuitization only earns mortality credits from the later date of purchase. Mortality rates increase with age, so the advantage of the ALDA over simply delaying annuitization increases with the length of delay.

The above calculations assume that households undertake an "optimal" decumulation of unannuitized wealth. Rows eight to twelve show annuity equivalent wealth when the household adopts a rule of thumb strategy of consuming an equal amount of unannuitized wealth every period from retirement until the age the ALDA income commences. By comparing the entry for the naïve strategy with the corresponding entry for the optimal strategy, one can calculate how much worse off the household is as a result of behaving sub-optimally. Depending on coefficient of risk aversion, a household aged 60 purchasing an ALDA with payments commencing at age 85 would be only $0.8(1.103-1.095)$ percent to $1.1(1.059-1.048)$ percent worse off. The household does almost as well following this simple rule of thumb as it would were it to carefully calculate an optimal strategy.

Finally, rows thirteen to seventeen (sophisticated strategy) and eighteen to twenty two (naïve strategy) show the percent of initial wealth that a household should optimally spend on an ALDA, taking account of actuarial unfairness. A household aged 60 purchasing an ALDA with income payments commencing at age 85, and following a naïve decumulation strategy in the interim, should spend between 13.2 and 15.8 percent of its wealth on an ALDA, setting aside the remainder of its wealth for consumption between age 60 and 85 . For any given commencement age, the optimal proportion of current wealth that should be invested in the ALDA increases with both purchase age and degree of risk aversion, the latter effect resulting from the CRRA risk aversion parameter doubling as the inverse of the intertemporal elasticity of substitution. But most of the variation comes from the choice of commencement age and ALDA defaults can be set without knowledge of the household's degree of risk aversion. As noted above, the household would be assured of an income for life, even after it had completely depleted its financial wealth. 
The above calculations all assume a single risk free asset in which both the household and the insurance company invest. Blake, Cairns, and Dowd (2003) and Horneff, Mitchell, Maurer, and Stamos (2007) analyze the portfolio allocation and annuitization decision when variable immediate annuities are available. ${ }^{14}$ They show that variable immediate annuities are attractive because their return is enhanced by both the equity premium and mortality credits. One option might therefore be to offer both inflation-protected and equity linked ALDAs. One problem that immediately arises when households invest in risk assets is that households following a plan of consuming a fixed amount every period prior to the ALDA payments commencing cannot be certain when they will exhaust their financial assets. One solution, proposed by Huang, Milevsky, and Salisbury (2007) is for an ALDA that combines longevity with investment portfolio insurance. They envisage an ALDA that would commence payment when a hypothetical investment in some market index that had been subject to a periodic withdrawal of some pre-specified amount had been exhausted. But payments would be conditional on one or both members of the household being alive at that time.

Our results complement those of Scott, Watson, and Hu (2007). They assume that, for a variety of reasons, households might only want to annuitize part of their wealth. They show that a single individual who only want to annuitize, five, ten, or twenty percent of his wealth will be better off choosing an ALDA than regular or deferred annuitization or an optimal decumulation of unannuitized wealth and that spending only a small proportion of the household's wealth on an ALDA yields almost as great ALDA or annuity equivalent wealth as full annuitization. We do not constrain the proportion of wealth that is spent on ALDAs or other annuity products, and calculate the optimal proportion of wealth to spend on annuities, and the optimal ALDA commencement age.

\footnotetext{
${ }^{14}$ We contrast variable immediate annuities with variable deferred annuities. Deferred annuities lack the essential characteristic of an immediate annuity, namely the transfer of wealth from those who are unlucky enough to live unusually long. The mortality credits resulting from this transfer enable annuities to offer a higher return than similar unannuitized investments, particularly at older ages. Variable immediate annuities provide a lifetime income that increases or decreases if the return on the underlying investments exceeds or falls short of a specified rate.
} 


\section{Using ALDAs as a Default in 401(k) Plans}

Previous research has demonstrated the power of defaults to influence savings decisions, most notably the 401(k) participation decision (Beshears, Choi, Laibson, and Madrian (2007)), and the choice between a single and a joint life annuity in defined benefit pension plans (Johnson, Uccello, and Goldwyn (2003)). If it is believed that households are making inappropriate annuitization decisions, then one solution might be to default them into an ALDA at retirement. But the decision to purchase an ALDA may not be in the best interest of high mortality households and, unlike the 401(k) participation decision, is irrevocable. In this section we review previous research on the distributional consequences of mandatory annuitization. We then calculate the distributional consequences, in both money's worth and expected utility terms, of defaulting households into ALDAs.

Brown (2003) calculated the distributional consequences for single individuals with no pre-annuitized wealth of mandatory annuitization on uniform and actuarially fair terms. He found that for the average individual in high mortality groups, for example black males with less than a high school education, annuity money's worth would be substantially less than the premium paid. But the average individual in all groups would be better off in expected utility terms.

As Brown points out, group averages may conceal considerable within-group heterogeneity. Using the methodology developed in Gan, Hurd, and McFadden (2005), Gong and Webb (2006) constructed subjective mortality tables for each HRS individual, based on the individual's estimate of his or her probability of surviving to age $75 .{ }^{15}$ They

\footnotetext{
${ }^{15}$ To summarize, individuals in the HRS were asked to assess their probabilities of surviving to ages 75 and 85 , on a scale of one to ten in wave one, and a scale of one to 100 in subsequent waves.

The data suffers from serious focal response problems, with some individuals giving responses of 0.0 and 1.0. These focal responses cannot be used directly as the measure of true subjective survival probabilities, because the distribution of true responses should be continuous and the true probabilities cannot be literally zero or one.

Gan, Hurd, and McFadden (2005) proposed a Bayesian updating method for recovering subjective annual survival probabilities from the AHEAD panel of somewhat older individuals born before 1924. More specifically, they assumed that an individual's true belief regarding his or her survival probability is unknown to the econometrician. However, the econometrician does know the distribution of those beliefs the Bayesian "prior." The individual reports a survival probability based on, but not necessarily equal to, his true beliefs. The difference between his true and his reported beliefs represents measurement error. GHM use the self-reported survival probabilities to update the prior distribution and to obtain the posterior distribution. GHM then apply the mean of the posterior distribution as an individual's estimated subjective
} 
showed that these subjective life tables varied appropriately with known determinants of mortality, and aggregated closely to published mortality tables. They then used these tables to calculate annuity equivalent wealth for each HRS married couple household turning 65 between 1994 and 2000, taking account of longevity risk sharing within marriage and each household's proportion of pre-annuitized wealth. They showed that 16.5 percent of all households and 36.5 percent of those with less than a high school education would be worse off in expected utility terms as a result of mandatory annuitization on uniform and actuarially fair terms.

Using the same methodology, we calculate the whole distribution of ALDA and annuity money's worth for above sample, and then calculate ALDA equivalent wealth for a prototypical high mortality household. We first assume actual (or in the case of ALDAs, projected) levels of actuarial unfairness. ${ }^{16}$ But defaulting high mortality households into annuities or ALDAs may reduce the equilibrium level of actuarial unfairness, and mandating annuitization or the purchase of ALDAs might reduce it still further. ${ }^{17}$ To illustrate the distribution of money's worths under a program of mandatory annuitization of 401(k) plan balances or Social Security Individual Accounts, we alternatively assume that annuities and ALDAs are actuarially fair to households with population average mortality for the appropriate birth cohort.

Figure One shows the distribution of gains and losses, in money's worth terms, and as a percentage of annuitizable wealth, were couples in the HRS required to purchase joint life and two thirds survivor ALDAs and annuities at actual and projected levels of actuarial unfairness. The average household would perceive itself suffering a loss of 21.2 percent of its initial wealth as a result of annuitization, but only 7.3 percent as a result of

survival probability to the observed mortality data among the panel to estimate parameter values that best characterize each individual's belief as to his annual survival probabilities.

${ }^{16}$ We can't use the ALDA prices reported in Section Two because they relate to the 1942 and 1947 birth cohorts, and the HRS households are on average somewhat older. Each household's money's worth is calculated using annuity and ALDA prices appropriate to its particular birth year.

${ }^{17}$ The actual money's worth would depend not only on insurance company expenses and sales loads, but also on program design. Women, who on average live longer than men, have lower 401(k) plan balances and would also have lower Social Security Individual Account balances because of their lower lifetime earnings. But within each gender, there is a positive correlation between wealth and longevity. The relative impact of these two factors would depend on the detailed design of the program, and in particular whether annuities were on joint or single lives, and whether individuals were required to annuitize a proportion of their wealth, or only up to a fixed dollar amount. 
the purchase of the ALDA. At the $5^{\text {th }}$ percentile of the distribution of money's worth, the annuity and ALDA losses amount to 31.7 and 12.9 percent respectively. Purchase of an ALDA inflicts a much smaller loss on both average and high mortality households than the purchase of an annuity.

Figure Two shows the results of the same calculations when the annuity and ALDA are both actuarially fair. As one might expect, both the annuity and ALDA are perceived to be approximately actuarially fair by the average household - it would perceive itself as gaining 1.1 percent in money's worth terms from the annuity, and 1.4 percent from the ALDA. ${ }^{18}$ At the $5^{\text {th }}$ percentile, the 5.2 percent loss from the ALDA is much smaller than the 12.4 percent loss from the annuity.

But the above money's worth calculations are a poor guide as to the value high mortality households might place on ALDAs because they fail to take account of the longevity insurance they provide. To explore this question further, we calculate annuity and ALDA equivalent wealth to the household whose subjective mortality beliefs correspond to the $5^{\text {th }}$ percentile of the distribution of annuity money's worth. We assume the utility function in equation (1), a value of $\lambda$ of 0.5 , no pre-annuitized wealth, prevailing levels of actuarial unfairness, a coefficient of risk aversion of three, and that both husband and wife are aged 65 .

Our household has an annuity equivalent wealth of 0.990 at age 65 and would be marginally off were it to annuitize relative to an alternative of undertaking an optimal decumulation of unannuitized wealth, given its subjective mortality beliefs. ${ }^{19}$ The comparable value for a household with population average mortality in a slightly younger birth cohort, reported in Table Three, is $1.032 .^{20}$ The comparable figures at a coefficient of risk aversion of five are 1.038 and 1.073. Our finding illustrates the relatively small

\footnotetext{
${ }^{18}$ Survival probability data is missing for proxy interviewees who likely had higher than average mortality. We imputed missing data, but were probably not wholly successful in correcting for this source of bias. We are therefore not surprised to find that average perceived money's worth slightly exceeds the premium paid.

${ }^{19}$ We assume no pre-annuitized wealth, or equivalently that the consumption purchased with income from pre-annuitized wealth does not enter into the utility function, and similarly high mortality risk households where this was not the case, or which were less risk averse would generally be worse off.

${ }^{20}$ The value of 1.032 is slightly higher than the equivalent number of 1.024 in Table Three, reflecting the shorter life expectancy of this cohort.
} 
impact of subjective mortality beliefs on the value of annuitization, consistent with the findings of Brown (2003). ${ }^{21}$

We then consider the alternative of an ALDA commencing at age 85, using the naïve strategy of equal consumption every period from age 65 to 84 . The optimal allocation to the ALDA for this high mortality household is 0.190 , almost identical to that for a household in this birth cohort with population average mortality, illustrating how this could allocation could safely be used as a default. ALDA equivalent wealth is 1.059, compared with 1.078 for the average household. ALDA equivalent wealth is greater than 1.00, even for the high mortality household. Despite having high mortality, the household is better off purchasing an ALDA than undertaking an optimal decumulation of unannuitized wealth.

\section{Conclusion}

The ALDA's attractiveness is that it provides a lot of longevity insurance at a relatively low cost. It also makes decumulation much simpler during the period before the ALDA payments commence.

It remains to be seen whether such a product would overcome annuity aversion. One possible solution might be to make the purchase of an ALDA the default in 401(k) plans. But this has the potential to harm high mortality households that would rationally choose to hold their wealth in unannuitized form and undertake a rapid decumulation of that wealth over their relatively short life expectancy. Our calculations indicate that, even when evaluated in money's worth terms, defaulting high mortality households into ALDAs would cause relatively little harm. This is because although ALDAs would have a low money's worth in the hands of such households, they would only invest a small proportion of their total wealth in them. But in expected utility terms, even high mortality households might be better off, indicating that concerns that the ALDA might be inappropriate for high mortality households may be misplaced.

Our calculations assume a single risk-free asset. In practice, households must not only decide whether and when to purchase an annuity or ALDA, but also how to allocate

\footnotetext{
${ }^{21}$ Annuity and ALDA equivalent wealth would be considerably lower if one incorporated pre-annuitized wealth into the utility function.
} 
both annuitized and unannuitized wealth between stocks and bonds. A useful extension of our research would therefore be to construct a numerical optimization model in which households faced not only a choice between ALDAs and unannuitized wealth, but also a decision as to what proportion of total wealth to hold in stocks, and how to vary that proportion over the course of retirement. 


\section{Bibliography}

Beshears, John, James J. Choi, David Laibson, and Brigitte C. Madrian. 2007. The Importance of Default Options for Retirement Savings Working Paper

Blake, David, Andrew Cairns, and Kevin Dowd. 2003. Pensionmetrics 2:

Stochastic Pension Plan Design During the Distribution Phase" Insurance: Mathematics and Economics 33 pp29-47

Brown, Jeffrey R. and James Poterba 2000. "Joint Life Annuities and Annuity Demand by Married Couples.” Journal of Risk and Insurance, 67(4): 527-53.

Brown, J., Warshawsky, M. 2001. "Longevity Insured Retirement Distributions from Pension Plans: Market and Regulatory Issues.” Gale, W., Shoven, J., Warshawsky, M. eds. Public Policies and Private Pensions, Brookings Institution, 2003. .

Brown, Jeffrey R. 2003. "Redistribution and Insurance: Mandatory Annuitization with Mortality Heterogeneity" Journal of Risk and Insurance, Vol.70, No. 1, 17-41.

DeNardi, Mariacristina, Eric French, and John Bailey Jones. 2006. Differential Mortality, Uncertain Medical Expenses, and the Saving of Elderly Singles National Bureau of Economic Research Working Paper No. 12554

Dushi, Irena and Anthony Webb. 2004. "Household Annuitization Decisions: Simulations and Empirical Analyses" Journal of Pension Economics and Finance 3(2)

Finkelstein, Amy and James Poterba. Adverse Selection in Insurance Markets: Policyholder Evidence from the U.K. Annuity Market Journal of Political Economy, 2004. Vol. 112(1): 183-208.

Friedberg, Leora and Anthony Webb. 2007. Life Is Cheap: Using Mortality Bonds to Hedge Aggregate Mortality Risk, The B.E. Journal of Economic Analysis \& Policy: Vol. 7 : Iss. 1 (Topics), Article 31.

Available at: http://www.bepress.com/bejeap/vol7/iss1/art31 Gan, L., Hurd, M. McFadden, D. 2005. "Individual Subjective Survival Curves" Analyses in the Economics of Aging. Ed. Wise D. pp. 377-402 (Chicago, University of Chicago Press)

Gan, L., Hurd, M. McFadden, D. 2005. Individual Subjective Survival Curves Analyses in the Economics of Aging. Ed. Wise D. pp. 377-402 (Chicago, University of Chicago Press) 
Gong, Guan, and Anthony Webb 2006 "Mortality Heterogeneity and the Distributional Consequences of Mandatory Annuitization" Center for Retirement Research Working Paper 2006-11

Gustman, Alan, and Thomas Steinmeier. 2001. "How Effective is Redistribution Under the Social Security Benefit Formula" Journal of Public Economics, 82: 1-28

Horneff, Wolfram J., Raimond H. Maurer, Olivia H. Mitchell, and Michael Z. Stamos. 2006. "Money in Motion: Dynamic Portfolio Choice in Retirement" Pension Research Council Working Paper 2007-7

Huang, Huaxiong, Moshe Arye Milevsky, and Tom Salisbury. 2007. "A Different Perspective on Retirement Income Sustainability: Introducing the Ruin Contingent Life Annuity" Schulich School of Business, York University. Unpublished Working Paper.

Johnson, Richard W., Cori E. Uccello, and Joshua H. Goldwyn. 2003. Single Life Vs Joint and Survivor Pension Payout Options: How Do Married Retirees Choose? Urban Institute. Final Report to the Society of Actuaries and the Actuarial Foundation

Lee, Ronald and Lawrence R. Carter. 1992. Modeling and Forecasting U.S. Mortality. Journal of the American Statistical Association 87(419): 659-671.

Milevsky, Moshe 2005 "Real Longevity Insurance With a Deductible:

Introduction to Advanced-Life Delayed Annuities (ALDA)" North American Actuarial Journal, Vol. 9 No. 4 pp 109-122

Mitchell, Olivia, James Poterba, Mark J. Warshawsky and Jeffrey J. Brown. 1999. "New Evidence on the Money's Worth of Individual Annuities," American Economic Review, Vol. 89 No. 5, pp.1299-1318.

Scott, Jason, S. John G. Watson, and Wei-Yin Hu. 2007. Efficient Annuitization: Optimal Strategies for Hedging Mortality Risk Pension Research Council Working Paper WP2007-09 
Table One: Comparison of ALDA Equivalent Wealth With Annuity Equivalent Wealth - Sophisticated Strategy

\begin{tabular}{|c|c|c|c|c|c|}
\hline \multicolumn{2}{|l|}{ Risk Aversion } & $\overline{2}$ & $\overline{3}$ & $\overline{4}$ & $\overline{5}$ \\
\hline \multicolumn{6}{|c|}{ Annuity or ALDA purchased at age 60} \\
\hline Annuity equivalent wealth & & 1.216 & 1.251 & 1.274 & 1.291 \\
\hline \multirow[t]{10}{*}{ ALDA com mecing at age } & 70 & 1.206 & 1.240 & 1.265 & 1.291 \\
\hline & & $95.4 \%$ & $95.7 \%$ & $96.6 \%$ & $100.0 \%$ \\
\hline & 75 & 1.191 & 1.224 & 1.246 & 1.269 \\
\hline & & $88.3 \%$ & $89.0 \%$ & $89.8 \%$ & $92.4 \%$ \\
\hline & 80 & 1.167 & 1.197 & 1.218 & 1.234 \\
\hline & & $77.3 \%$ & $78.6 \%$ & $79.4 \%$ & $80.6 \%$ \\
\hline & 85 & 1.134 & 1.161 & 1.178 & 1.190 \\
\hline & & $61.9 \%$ & $64.2 \%$ & $65.0 \%$ & $65.2 \%$ \\
\hline & 90 & 1.093 & 1.116 & 1.130 & 1.138 \\
\hline & & $43.0 \%$ & $46.1 \%$ & $47.3 \%$ & $47.5 \%$ \\
\hline Proportion of initial wealth & 70 & 0.522 & 0.527 & 0.531 & 0.538 \\
\hline \multirow[t]{4}{*}{ spent on ALDA } & 75 & 0.343 & 0.348 & 0.351 & 0.354 \\
\hline & 80 & 0.204 & 0.207 & 0.209 & 0.210 \\
\hline & 85 & 0.103 & 0.105 & 0.106 & 0.107 \\
\hline & 90 & 0.042 & 0.042 & 0.043 & 0.043 \\
\hline \multicolumn{6}{|c|}{ Annuity or ALDA purchased at age 65} \\
\hline Annuity equivalent wealth & & 1.264 & 1.307 & 1.336 & 1.356 \\
\hline \multirow[t]{10}{*}{ ALDA commencing at age } & 70 & 1.260 & 1.303 & 1.331 & 1.351 \\
\hline & & $98.5 \%$ & $98.8 \%$ & $98.5 \%$ & $98.6 \%$ \\
\hline & 75 & 1.244 & 1.286 & 1.317 & 1.332 \\
\hline & & $92.7 \%$ & $93.3 \%$ & $94.6 \%$ & $93.3 \%$ \\
\hline & 80 & 1.216 & 1.254 & 1.280 & 1.315 \\
\hline & & $82.0 \%$ & $82.8 \%$ & $83.4 \%$ & $88.3 \%$ \\
\hline & 85 & 1.174 & 1.209 & 1.233 & 1.246 \\
\hline & & $66.0 \%$ & $68.1 \%$ & $69.6 \%$ & $69.2 \%$ \\
\hline & 90 & 1.120 & 1.149 & 1.167 & 1.180 \\
\hline & & $45.4 \%$ & $48.5 \%$ & $49.8 \%$ & $50.5 \%$ \\
\hline \multirow{5}{*}{$\begin{array}{c}\text { Proportion of initial wealth } \\
\text { spent on ALDA }\end{array}$} & 70 & 0.703 & 0.707 & 0.709 & 0.711 \\
\hline & 75 & 0.459 & 0.465 & 0.468 & 0.468 \\
\hline & 80 & 0.270 & 0.263 & 0.276 & 0.280 \\
\hline & 85 & 0.135 & 0.137 & 0.138 & 0.138 \\
\hline & 90 & 0.053 & 0.054 & 1.000 & 0.054 \\
\hline
\end{tabular}

Notes: Rate of time preference and real rate of interest both equal 2.35\%. Husband and wife both aged 60 (65) with 1947 (1942) birth cohort mortality. Complementarity of consumption $(\lambda)=0.5$. Annuity has $2 / 3$ survivor benefit 
Table Two: Comparison of ALDA Equivalent Wealth With Annuity Equivalent Wealth - Naïve Strategy

\begin{tabular}{|c|c|c|c|c|c|}
\hline \multicolumn{2}{|l|}{ Risk Aversion } & 2 & 3 & 4 & 5 \\
\hline \multicolumn{6}{|c|}{ Annuity or ALDA purchased at age 60} \\
\hline Annuity equivalent wealth & & 1.216 & 1.251 & 1.274 & 1.291 \\
\hline \multirow[t]{10}{*}{ ALDA commencing at age } & 70 & 1.206 & 1.240 & 1.262 & 1.278 \\
\hline & & $95.4 \%$ & $95.6 \%$ & $95.7 \%$ & $95.8 \%$ \\
\hline & 75 & 1.189 & 1.222 & 1.243 & 1.259 \\
\hline & & $87.7 \%$ & $88.4 \%$ & $88.8 \%$ & $89.1 \%$ \\
\hline & 80 & 1.162 & 1.193 & 1.213 & 1.227 \\
\hline & & $75.0 \%$ & $76.8 \%$ & $77.7 \%$ & $78.2 \%$ \\
\hline & 85 & 1.121 & 1.150 & 1.168 & 1.181 \\
\hline & & $56.0 \%$ & $59.7 \%$ & $61.4 \%$ & $62.4 \%$ \\
\hline & 90 & 1.064 & 1.091 & 1.107 & 1.119 \\
\hline & & $29.7 \%$ & $36.1 \%$ & $39.2 \%$ & $40.9 \%$ \\
\hline Proportion of initial wealth & 70 & 0.522 & 0.527 & 0.530 & 0.531 \\
\hline \multirow[t]{4}{*}{ spent on ALDA } & 75 & 0.343 & 0.348 & 0.350 & 0.352 \\
\hline & 80 & 0.203 & 0.207 & 0.208 & 0.209 \\
\hline & 85 & 0.103 & 0.109 & 0.106 & 0.106 \\
\hline & 90 & 0.041 & 0.042 & 0.042 & 0.042 \\
\hline \multicolumn{6}{|c|}{ Annuity or ALDA purchased at age 65} \\
\hline Annuity equivalent wealth & & 1.264 & 1.307 & 1.336 & 1.356 \\
\hline \multirow[t]{10}{*}{ ALDA commencing at age } & 70 & 1.260 & 1.303 & 1.331 & 1.351 \\
\hline & & $98.5 \%$ & $98.5 \%$ & $98.6 \%$ & $98.6 \%$ \\
\hline & 75 & 1.243 & 1.285 & 1.312 & 1.330 \\
\hline & & $92.4 \%$ & $92.8 \%$ & $93.0 \%$ & $92.8 \%$ \\
\hline & 80 & 1.212 & 1.251 & 1.276 & 1.295 \\
\hline & & $80.4 \%$ & $81.7 \%$ & $82.4 \%$ & $82.7 \%$ \\
\hline & 85 & 1.161 & 1.197 & 1.220 & 1.236 \\
\hline & & $60.9 \%$ & $64.1 \%$ & $65.5 \%$ & $66.4 \%$ \\
\hline & 90 & 1.088 & 1.121 & 1.141 & 1.156 \\
\hline & & $33.3 \%$ & $39.3 \%$ & $42.1 \%$ & $43.7 \%$ \\
\hline \multirow{5}{*}{$\begin{array}{c}\text { Proportion of initial wealth } \\
\text { spent on ALDA }\end{array}$} & 70 & 0.703 & 0.707 & 0.709 & 0.711 \\
\hline & 75 & 0.459 & 0.464 & 0.467 & 0.468 \\
\hline & 80 & 0.269 & 0.273 & 0.275 & 0.276 \\
\hline & 85 & 0.134 & 0.136 & 0.137 & 0.138 \\
\hline & 90 & 0.052 & 0.053 & 0.053 & 0.053 \\
\hline
\end{tabular}

Notes: See Table One 
Table Three - Alternative Strategies Relative to a Base Case of Unannuitized Decumulation - Incorporating Actuarial Unfairness

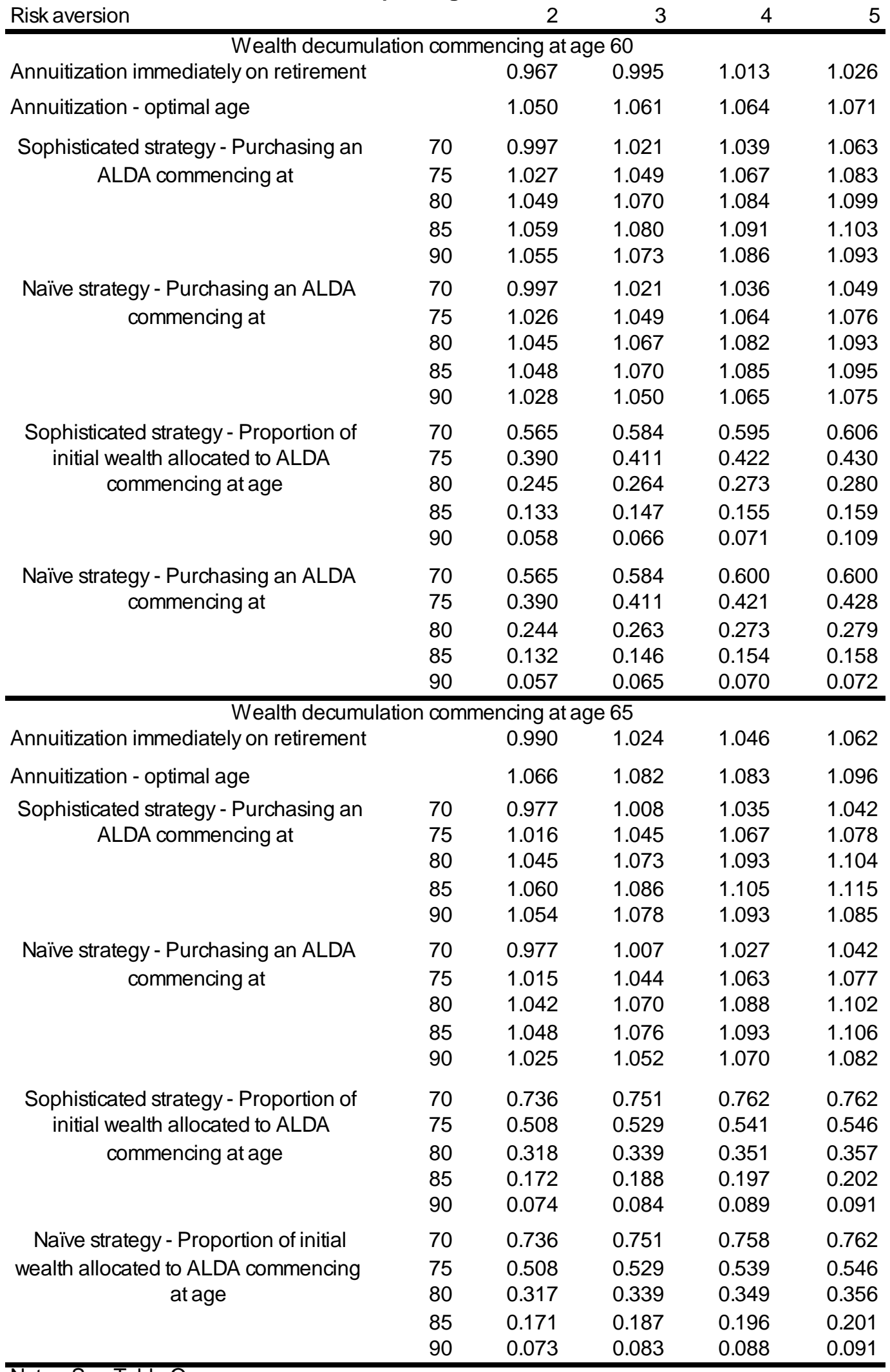

Notes: See Table One 

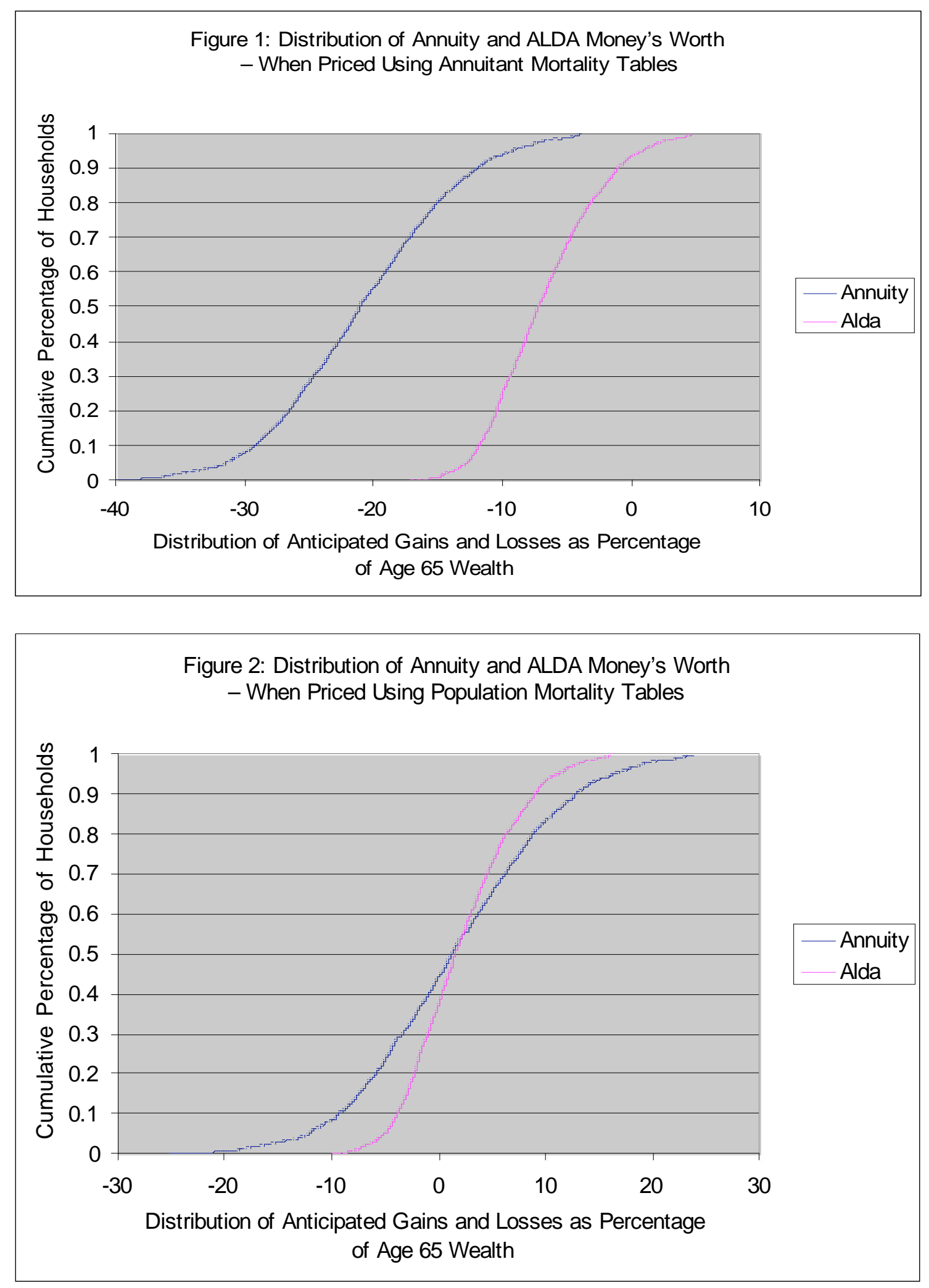


\section{RECENT WORKING PAPERS FROM THE}

\section{CENTER FOR RETIREMENT RESEARCH AT BOSTON COLLEGE}

Population Aging, Labor Demand, and the Structure of Wages

Margarita Sapozhnikov and Robert K. Triest, September 2007

Work at Older Ages: Is Raising the Early Retirement Age an Option for Social Security Reform?

John A. Turner, August 2007

The Labor Supply of Older Americans

Alicia H. Munnell and Steven A. Sass, May 2007

Why Do Japanese Workers Remain in the Labor Force So Long?

John B. Williamson and Masa Higo, May 2007

Literacy, Trust and the 401(k) Savings Behavior

Julie R. Agnew, Lisa Szykman, Stephen P. Utkus, and Jean A. Young, May 2007

The Recent Evolution of Pension Funds in the Netherlands: the Trend to Hybrid DB-DC Plans and Beyond

Eduard H.M. Ponds and Bart van Riel, May 2007

Demographic Influences on Saving-Investment Balances in Developing and Developed Economies

Ralph C. Bryant, May 2007

Social Security Spouse and Survivor Benefits for the Modern Family

Melissa M. Favreault and C. Eugene Steuerle, February 2007

How Economic Security Changes During Retirement

Barbara Butrica, February 2007

International Investment for Retirement Savers: Historical Evidence on Risk and Returns

Gary Burtless, February 2007

Job Changes at Older Ages: Effects on Wages, Benefits, and other Job Attributes Richard W. Johnson and Janette Kawachi, February 2007 